\title{
Modernidade e visualidade no projeto editorial da revista 0 Cruzeiro (1928-1945)
}

\author{
MARINÊS RIBEIRO DOS SANTOS \\ THAÍS MANNALA
}

\section{Resumo}

O Cruzeiro foi uma revista semanal ilustrada, publicada no Brasil entre 1928 e 1975. O presente artigo tem como foco de estudo o desenvolvimento do projeto editorial do semanal desde o lançamento do primeiro número até o final da Segunda Grande Guerra, em 1945. Abordando aspectos relacionados às possibilidades tecnológicas dos meios de impressão, ao uso de fotografias, ilustrações e recursos tipográficos na diagramação das páginas do semanal, objetiva-se apresentar algumas das estratégias utilizadas na construção de uma cultura visual moderna associada aos conteúdos veiculados. Em circulação durante um período em que o país desejava modernizar-se, a revista ilustrada $O$ Cruzeiro contribuiu para a incorporação de novos hábitos de leitura no cotidiano das pessoas, principalmente mediante a apresentação de formas características de articulação entre texto e imagem.

Palavras-chave:

Revista O Cruzeiro, design gráfico brasileiro, tecnologia 


\title{
Visuality and modernity on the design project of the 0 Cruzeiro illustrated magazine (1928-1945)
}

\author{
MARINÊS RIBEIRO DOS SANTOS \\ THAÍS MANNALA
}

\begin{abstract}
O Cruzeiro was a brazilian illustrated magazine published between 1928 and 1975. In this article, we explore how this publication is exemplar in the articulation of graphical and editorial practices, contributing in some ways to the construction of a modern visual culture in Brazil. We delimit our analysis to a period that goes from the publication of its first issue to the end of the Second World War, in 1945, a time when several countrywide modernization trends took place. Our focuses concern the particular and interrelated employment of photography, graphic illustrations, typography and printing technologies on its essays. We can say that the articulation of textual and imagetic resources contributed to the construction of new practices of reading in everyday life.
\end{abstract} graphic design, technology 


\section{Introdução}

O presente artigo objetiva explorar alguns aspectos da linguagem gráfica utilizados pela revista $O$ Cruzeiro durante os seus primeiros vinte anos de circulação. Com foco nas edições que circularam no entreguerras (1920-1940), pretende-se entender a importância que os elementos gráficos adquiriram para a formação de uma cultura visual moderna no Brasil, contribuindo na difusão de ideais e estilos de vida. É por meio da visualidade que as seções temáticas ganharam forma, atraindo olhares específicos, como por exemplo, do público feminino, que contava com um espaço privilegiado nas edições do O Cruzeiro. Logo, pensando na relação do semanal com a modernidade, o uso de linguagens capazes de traduzir a ideia de progresso era essencial para a sua consolidação no mercado editorial da época.

O período entreguerras (1920-1940) foi escolhido como recorte temporal pela sua importância no que concerne ao desenvolvimento da indústria gráfica no Brasil. Segundo Rafael Cardoso (200o), foi durante as primeiras décadas do século XX que o advento das novas tecnologias se mostrou significativo, com a expansão do parque industrial nacional e o desenvolvimento do rádio e do cinema, cuja associação com cartazes, anúncios publicitários e revistas ilustradas abriram um novo campo de possibilidades para o design.

A modernidade ${ }^{1}$ era o carro-chefe do semanal O Cruzeiro, cujos ideais eram traduzidos, entre outras estratégias, por meio da veiculação de novos recursos visuais. Sendo assim, com vistas a ressaltar as estratégias discursivas empregadas pelo periódico na formação de uma cultura visual moderna associada às mídias impressas de circulação de massa, pretende-se destacar a associação entre o desenvolvimento das 
técnicas de impressão as formas de uso das imagens e os conteúdos veiculados pelo semanal. Serão focalizados aspectos pertinentes ao projeto editorial da revista, tais como a divisão das seções temáticas, o uso da fotografia, da ilustração e da tipografia, a relação dos recursos gráficos com os conteúdos.

\section{A revista ilustrada $O$ Cruzeiro}

Com o desenvolvimento da indústria gráfica nacional, houve a promoção de uma nova concepção visual para a imprensa e para os impressos, tornando-os segmentos econômicos polivalentes. Neste contexto, os impressos adquiriram importância como meios divulgadores dos ideais de modernidade, ao mesmo tempo em que são parte integrante dela (SILVA, 2007). Uma das principais mudanças observadas está na articulação entre texto e imagem. $\mathrm{O}$ aperfeiçoamento tipográfico aliado aos avanços nas técnicas de ilustração caracterizou um aspecto relevante nas inovações qualitativas e quantitativas de impressão. Como decorrência, são as inúmeras as revistas ilustradas que surgem nas primeiras décadas do século XX, cuja expansão e difusão estão intimamente ligadas ao processo de massificação e modernização da produção e do consumo no Brasil (CARDOSO, 2000; SILVA, 2007).

As revistas ilustradas possuíam uma abordagem diversificada em relação aos outros meios de comunicação impressos, como o livro e o jornal. Este tipo de publicação trouxe consigo a construção de uma nova cultura visual, entendida como moderna, ampliando o acesso às informações. $\mathrm{O}$ aperfeiçoamento tecnológico, que permitiu a impressão simultânea de imagens e textos, possibilitou uma redução nos custos, barateando o produto final e flexibilizando a diagramação. Ao se tornarem mais atraentes e com preço acessível, as revistas ilustradas promoveram "uma democratização da cultura visual, estimulando o hábito da leitura e o interesse das classes menos favorecidas pela alfabetização" (SOBRAL, 2007, p. 30). Atuando no imaginário coletivo, as revistas ilustradas difundiram e questionaram hábitos e valores, alterações no meio urbano e na vida cultural da população, bem como contribuíram na modificação ou no reforço de códigos sociais vigentes, exercendo influência nos âmbitos público e privado do país (SOBRAL, 2007).

A revista semanal ilustrada $O$ Cruzeiro esteve em circulação entre os anos de 1928 a 1975, sendo a primeira do segmento com alcance nacional. Lançado pelo jornalista português Car- 
los Malheiro Dias, o título foi comprado pelo empresário Assis Chateaubriand, uma personalidade de grande importância no Brasil naquele período. Conhecido como Chatô, o empresário exerceu influência na vida social e política do país principalmente por meio dos Diários Associados, grupo de comunicação que englobava jornais, revistas, emissoras de rádio e televisão e agência telegráfica. Dentre seus maiores e mais célebres empreendimentos estão a TV Tupi e a revista O Cruzeiro.

\section{Modernidade e visualidade em revista}

A configuração gráfica do $O$ Cruzeiro no recorte temporal pesquisado pode ser dividida em dois momentos: o projeto inicial da década de 1930 e a reformulação capitaneada por de Jean Manzon $^{2}$ na década de 1940 . No primeiro momento tem-se a valorização dos recursos tecnológicos usados na impressão das publicações, conforme explica um anúncio veiculado pela revista no dia 30 de maio de 1931, cuja vinheta, centralizada abaixo de uma ilustração com características do Art Deco e do Cubismo $^{3}$ consiste no exposto a seguir:

[O Cruzeiro dispõe] dos mais aperfeiçoados mecanismos e pessoal técnico, executam-se com a máxima perfeição quaisquer trabalhos em tricromia, rotogravura, composição, impressão e encadernação, bem como toda a espécie de trabalhos comerciais, revistas, catálogos, álbuns, folhinhas, livros, publicações de arte, pelos preços mais razoáveis.

Com um maquinário e técnicos de "primeira classe", O Cruzeiro passou, inicialmente, a explorar o potencial das oficinas gráficas, aceitando inclusive encomendas de trabalhos externos a fim de obter lucros extras (NETTO, 1998). A qualidade de impressão do semanal em sua primeira fase é resultado de:

[...] quatro grandes impressoras rotoplanas, uma rotogravura rotoplana (a primeira a ser montada no Brasil), seis linotipos modernos, de última geração, caixas de tipos avulsos, duas grampeadoras e demais peças de uma oficina de composição e impressão (NETTO, 1998, p. 36).

A rotogravura, como um dos símbolos da modernidade e do progresso, possui grande relevância para o periódico. Uma reportagem veiculada no dia 24 de novembro de 1928 explica como procedeu a divulgação do semanal antes da circulação 
da primeira edição destacando a exibição nos cinemas de um pequeno filme que mostrava uma máquina Multicolor em funcionamento 4 (MORAIS, 1994). Para o semanal, o processo de impressão em uma máquina de rotogravura caracteriza-se como a "última palavra da engenharia ao serviço das artes gráficas, [a máquina] é por si só o símbolo mecânico de Cruzeiro, na ilimitada aspiração de progresso que nos anima" (O CRUZEIRO, 24 nov. 1928, p. 11). Em contrapartida, o aproveitamento da máquina era baixo, tendo em vista a pouca porcentagem de cores usadas no miolo, restrito a poucas páginas em que se adicionava uma cor além dos tons de preto. A partir dos anos 40, passa-se a imprimir um caderno ${ }^{5}$ do semanal em quadricromia (com exceções, acrescentava-se meio caderno), geralmente destinado às reportagens de maior importância ou às colunas com grande popularidade.

Em 1939, - um pouco antes da entrada de Jean Manzon em O Cruzeiro - Chateaubriand encomendou uma nova máquina vinda do Estados Unidos: uma rotativa Hoe, "ainda mais avançada que a Multicolor", sendo ela "capaz de imprimir em poucas horas 300 mil exemplares de um caderno de oito páginas inteiramente em quatro cores" (MORAIS, 1994, p. 369). Com o intuito de agilizar a impressão do periódico, sem causar mudanças significativas, Chateaubriand objetivava principalmente entrar no mercado de quadrinhos com a revista $O$ Guri, sendo a primeira do segmento a ser impressa em quatro cores em território nacional (JÚNIOR, 2004).

Com a entrada de Jean Manzon na equipe do periódico em meados de 1942, ocorreram mudanças não somente na configuração estética do $O$ Cruzeiro, como também na maneira de fazer reportagens. Suas experiências anteriores como fotógrafo trouxeram consigo concepções da imprensa europeia, sobretudo da requintada Match, impressa sobre papel couchê de alta qualidade (MORAIS, 1994). Sua primeira opinião sobre o projeto editorial do semanal foi de desapontamento. Nas palavras de Manzon: "Quando cheguei em O Cruzeiro, a reportagem fotográfica no Brasil era inexistente. Havia um atraso muito grande, a paginação era confusa e [havia] sobretudo muito receio de mudar" (MEDEIROS apud CARVALHO, 2001, p. 63).

Este trecho exprime a concepção do repórter sobre o tipo de mudança que o periódico necessitava, pois, apesar de sua popularidade, as vendas encontravam-se abaixo do esperado. Dentro deste panorama, Manzon recebe carta branca por parte de Chateaubriand para trabalhar com os aspectos estéticos do 
impresso. Ao colocar em prática suas ideias, colabora para a alteração do modo de fazer jornalismo no Brasil, incentivando a fotorreportagem. A principal característica deste tipo de jornalismo é a "dobradinha" repórter-fotógrafo, em que um escreve e o outro ocupa-se da fotografia (MORAIS, 1994, p. 418). Com a implementação dos novos métodos jornalísticos, tem-se o aprimoramento da qualidade editorial e da configuração visual da revista, valorizando a fotografia e trazendo maior efeito de realismo e dramaticidade às reportagens.

Os temas abordados pela parceria firmada entre Jean Manzon e o fotógrafo David Nasser eram os mais diversos e sempre buscavam o exótico e o sensacional. Desde reportagens sobre a encantadora de cobras Luz Del Fuego ${ }^{6}$ e sobre os índios Xavantes $^{7}$, - que trouxeram fama à dupla - passando pelas matérias sobre a realidade das favelas em expansão do Rio de Janeiro ${ }^{8}$, a dupla concebeu o "moderno" não somente pela diferenciação no modo de fazer jornalismo, mas também por que facilitavam a identificação com o público leitor, que podia ver o inusitado, bem como o seu cotidiano retratado nas páginas do semanal.

\section{O projeto editorial}

Durante sua trajetória, O Cruzeiro foi impresso no formato 330 x $244 \mathrm{~mm}$. Em sua fase inicial, a revista semanal foi caracterizada pelo "luxo editorial jamais visto no Brasil", devido ao uso de "cores sobre papel couchê de primeira classe" (NETTO, 1998, p. 37). Nesse período, o periódico era composto por, em média, 50 páginas, aumentando este número para 100 a partir de 1940.

De início tem-se um projeto gráfico com sobreposições de imagens, com pouca preocupação com a hierarquia de informações. Visando o aproveitamento dos espaços nas páginas, os anúncios chegavam a "competir" com o conteúdo pela atenção do público leitor. Para Carvalho (2001, p. 63) a configuração visual do semanal, até meados de 1940, apresentava-se da seguinte forma:

Desordenadamente ilustrada, com profusão de fotografias, $O$ Cruzeiro, oferecia rica variedade de temas: farta cobertura da Segunda Guerra Mundial; acontecimentos sociais de toda ordem; moda, beleza e culinária; muito cinema americano; competições esportivas; notícias requentadas. Prevalecia, no texto, o chamado "nariz-de-cera" - aquelas longas introduções que antecediam a informação propriamente dia. Tudo isso, apresentado num design confuso, sem unidade, em meio a muitos anúncios, matérias pagas ou sem caracterização publicitária. 
Em contrapartida ao relato anterior, pode-se notar que o semanal buscava explorar ao máximo os recursos modernos possibilitados pelas tecnologias de que dispunha. Além disso, recorria aos ícones que representavam a modernidade no início do século XX. Nas primeiras edições, O Cruzeiro publica reportagens e contos futuristas, buscando prever como se configuraria o Brasil em um futuro próximo, exaltando os arranha-céus e a tecnologia a serviço das pessoas (Figura 1), ou apresentando ao público leitor matérias sobre artistas plásticos e suas obras. Em alguns casos tem-se a exploração de recursos por meio de efeitos tipográficos, conforme exemplificado na Figura 1, em que os zeros do ano 2000 estão incorporados à paisagem.

Figura 1

Matéria sobre como seria o Brasil no futuro (O CRUZEIRO, Io nov. 1928, p. 25)

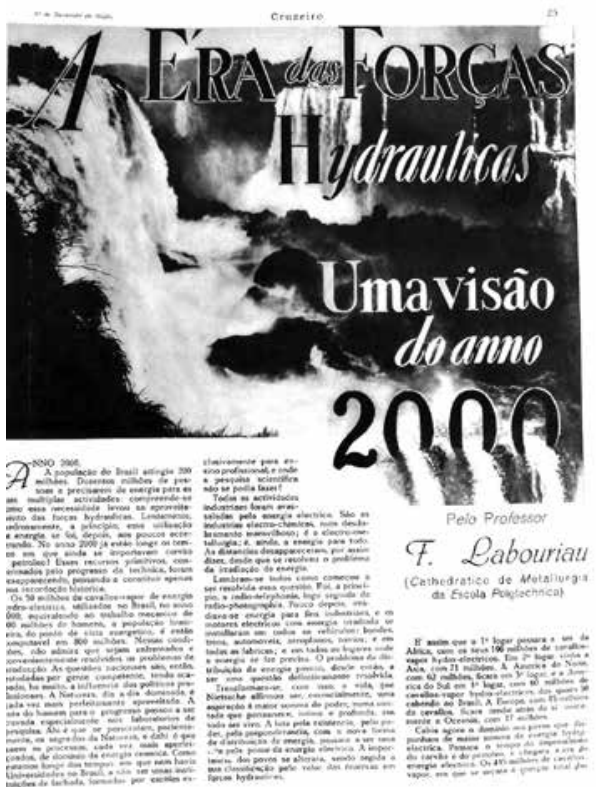

Um aspecto comum nos artigos veiculados no semanal é o recurso da descontinuidade. Este recurso consiste em distribuir ao longo do exemplar vários trechos do texto, com o intuito de fazer com que as pessoas explorem a totalidade da revista. Visa, também, proporcionar o preenchimento das páginas com espaços vendidos para publicidade. No exemplo veiculado na edição do dia 30 de novembro de 1940 (Figuras 2, 3 e 4), o conto "O Coração é um traidor", é dividido em seis partes: inicia na página 19 (Figura 2), retorna à página 6 (Figura 2), avança para a página 10 (Figura 3), depois para as páginas 14 (Figura 3) e 18 (Figura 4), finalizando na página 38 (Figura 4). 

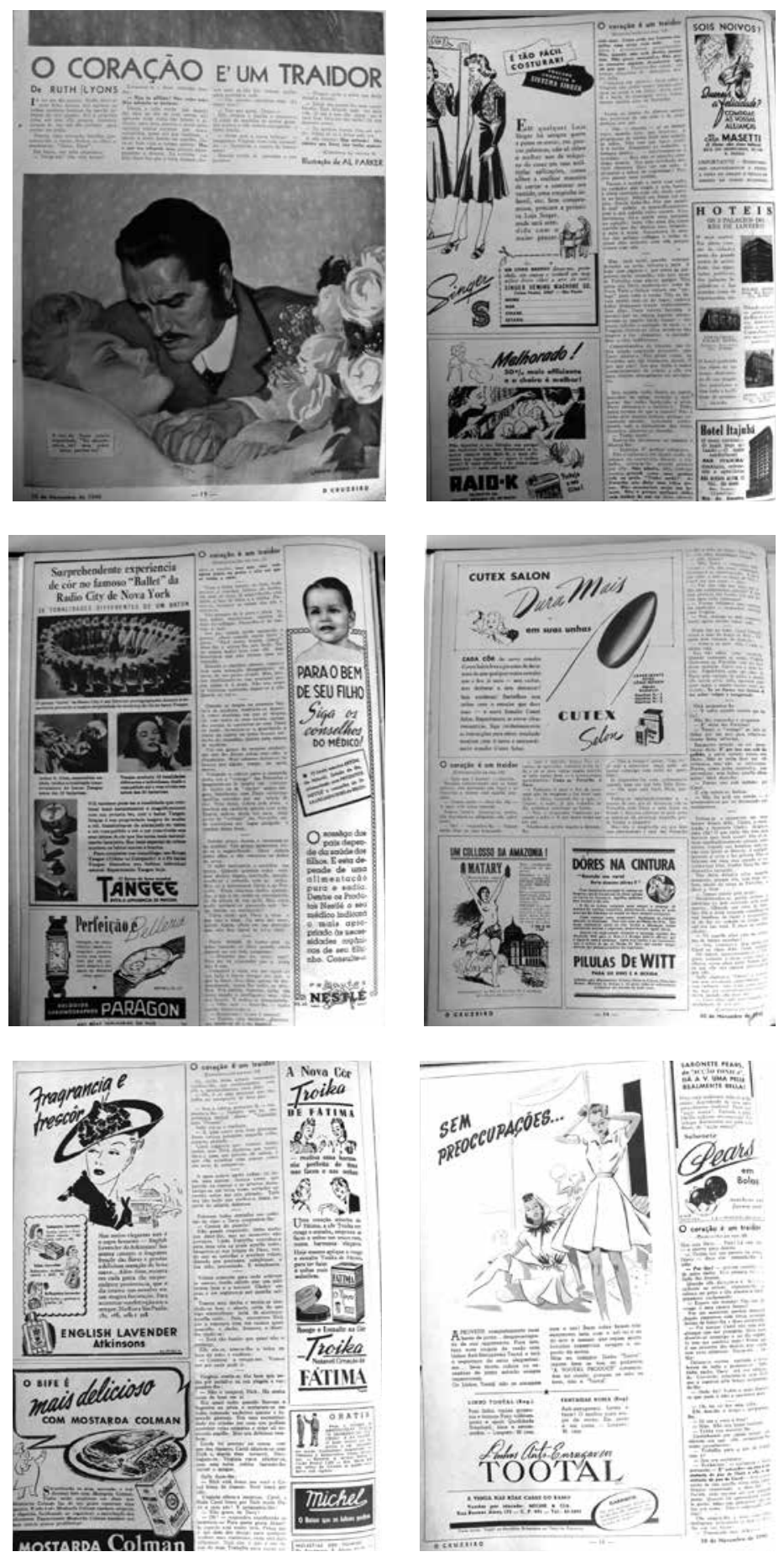
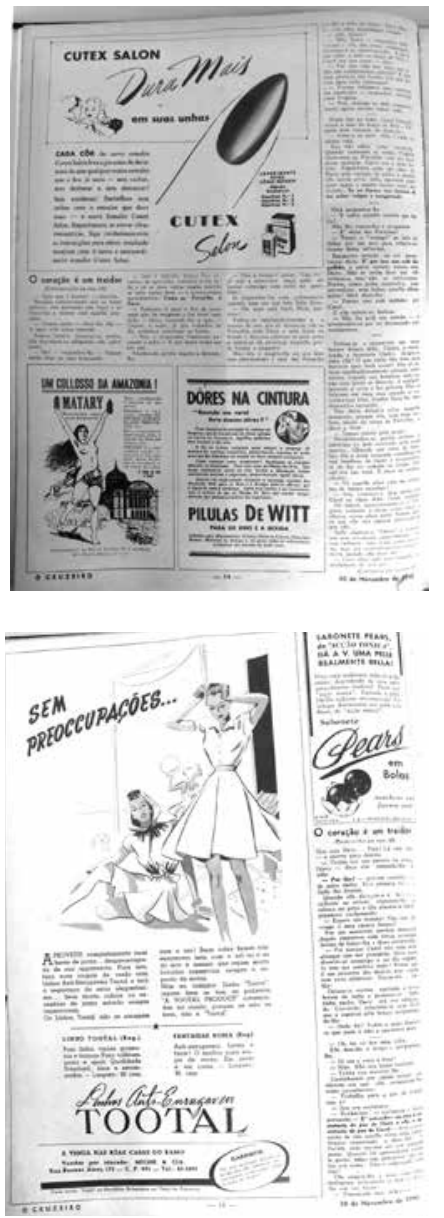

Figura 2

Página inicial e segunda parte do conto "O coração é um traídor". (O CRUZEIRO, 30 nov. 1940, p. 19 e 6)

Figura 3

Terceira e quarta partes do conto. (O CRUZEIRO, zo nov. 1940, p. 10 e 14)

\section{Figura 4}

Quinta e sexta partes do conto. (O CRUZEIRO, 30 nov. 1940, p. 18 e 38$)$ 
Nas páginas que trazem a continuação do conto, tem-se os anúncios publicitários dispostos em colunas, variando na largura. Nos anúncios, o uso de ilustrações e fotografias é constante, visando a relação do artefato vendido com o cotidiano, - principalmente focado no público feminino - ou referenciando padrões estrangeiros, como no exemplo da Figura 4. A publicidade situada no canto superior esquerdo relaciona o nome do produto - English lavender de Atkinsons - à sua utilização nos meios elegantes, insinuando a ideia de que o que vem de fora transmite qualidade superior em relação ao nacional. Essa valorização do estrangeiro traduz um fenômeno de consumo vinculado ao cinema norte-americano e à indústria do entretenimento. Ainda sobre os anúncios direcionados para públicos femininos, segundo Higonnet (1991):

A publicidade servia-se da imagem [e da ilustração] para demonstrar os efeitos das mercadorias que oferecia, efeitos que nem sempre eram claramente ocasionados pelos produtos em $\mathrm{si}$, mas antes insistentemente associados a novos ideais femininos.

Francischett (2008, p. 3), ressalta a contribuição da revista na construção de uma cultura visual moderna associada às representações de feminilidades:

A grande visibilidade das mulheres nas capas de $O$ Cruzeiro e também nas fotorreportagens demonstra a transição de uma importante cultura de massas auditiva - na qual as imagens femininas são construídas através das vozes transmitidas pelo rádio - para uma cultura visual. As fotografias de mulheres passam da circulação restrita dos álbuns de família para os veículos de comunicação de ampla circulação pública (grifo no original)

Vale destacar que no $O$ Cruzeiro os anúncios publicitários eram tratados como elementos visuais constituintes da revista. A justificativa para essa prerrogativa pautava-se pelo aspecto histórico da modernidade vivenciada e registrada pelos editores nas publicações do semanário, conforme afirma a edição de número dois:

Em CRUZEIRO, os anúncios são parte integrante do texto e nele colocados como fatores indispensáveis à beleza e harmonia das páginas. É inútil encarecer o maior gráo de eficiência que dali resulta para a publicidade feita em nossas colunas. 
CRUZEIRO considera o anúncio como a mais palpitante documentação de uma época: dos seus costumes, da sua civilização, da sua prosperidade (O CRUZEIRO, 17 nov. 1928, p. 6o).

A predominância de anúncios publicitários no preenchimento de espaços ao longo dos trechos descontinuados do conto, comentada anteriormente, possivelmente tem a intenção de otimizar o conhecimento dos anúncios por parte do público leitor. Os anúncios em destaque privilegiam o público feminino, com conteúdos sobre a vida privada e pública das mulheres, entre eles a casa, os filhos, a beleza e a higiene pessoal. Estes tópicos estiveram presentes durante toda a trajetória do semanal e entre as décadas de 1920 a 1940 possuíam características específicas. Os conteúdos buscavam a associação dos produtos com imagens que remetessem a tipos específicos de realizações femininas, tais como atrair um pretendente, casar, educar os filhos ou simplesmente conseguir aceitação social, com o objetivo de trazer para as mercadorias sentimentos de satisfação e felicidade (HIGONNET, 1991).

\section{Ilustrações, fotografias e tipografia}

Durante o recorte temporal proposto, as ilustrações e as fotografias dividiram espaço nas páginas do $O$ Cruzeiro e possuem abordagens específicas na busca pela relação entre imagens e texto.

As imagens e as fotografias objetivavam atrair o público leitor, enriquecendo e buscando traduzir o conteúdo textual. Com as indústrias e os meios de comunicação estimulando o consumo de produtos seriados (pensando na revista como uma mídia editada em grande escala), uma estratégia eficaz para chamar a atenção consistia na inserção da fotografia e da ilustração, por meio das quais podiam ser exploradas as experiências pessoais de leitoras e leitores, nem sempre familiarizados com a linguagem letrada, na decodificação das mensagens expressas pictoricamente. A intenção era a de construir significados com a contribuição do aprimoramento dos recursos visuais, visando conquistar o grande público para o conteúdo contido nesse tipo de publicação (VELLOSO, 2010).

Conforme já foi dito, a revista $O$ Cruzeiro entra em circulação durante a consolidação da imprensa nos moldes do capitalismo industrial. No Brasil, a prática da fotografia era tida como hobby e ainda não se estabelecera plenamente como profissão. No início do século XX a linha entre a arte e a 
imprensa ilustrada era tênue. Muitos artistas prestavam serviços às revistas, promovendo um intercâmbio entre arte erudita e de massa, que se encontrava em expansão. Logo, foram muitos os colaboradores ilustres que participaram da construção visual do semanal. Dentre os artistas, pintores e caricaturistas que tiveram seus trabalhos publicados no $O$ Cruzeiro, destacam-se: Portinari, Di Cavalcanti, Santa Rosa, Djanira, Ismael Nery, Enrico Bianco, Emeric Marcier, Gilberto Trompowski, Anita Malfatti e J. Carlos, além de outros que contribuíram eventualmente (NETTO, 1998). O Cruzeiro também contava com um time fixo de ilustradores, cartunistas e fotógrafos. Péricles (Maranhão), Millôr Fernandes, Alceu Penna, Ziraldo e seu irmão Zélio, Fortuna (Reginaldo José de Oliveira), Alvarus (Álvaro Cotrim), Nassara (Antônio Gabriel Nássara), Orlando Mattos e o já citado Jean Manzon são algumas das personalidades que prestaram serviços ao semanário (NETTO, 1998).

O emprego da ilustração e da fotografia dependia das técnicas de impressão disponíveis no período. A ilustração e a fotografia eram tidas como importantes para a formação visual dos leitores, reforçando as condutas sociais promovidas pelo periódico. A ilustração, no começo do semanário, era mais utilizada do que a fotografia. Esta última, geralmente, era vinculada aos contos e às matérias informativas. Ornamentos eram usados com frequência, muitas vezes na forma de molduras, como artifício para enriquecer a página.

A ilustração, por vezes torna-se um meio eficaz de sátira e denúncia. A charge e o cartum são exemplos do uso do humor para satirizar a sociedade em geral. De início, O Cruzeiro "importava" as charges de periódicos estrangeiros, questão que posteriormente foi solucionada com a contratação de ilustradores e cartunistas nacionais. O cotidiano é o principal tema das charges e cartuns publicadas no semanal. A Figura 5 mostra charges veiculadas na segunda edição da revista. Com frases curtas, os desenhos ironizavam, por exemplo, as mudanças no espaço-tempo promovidas pela introdução do automóvel no dia a dia. Outro tema recorrente diz respeito ao comportamento feminino. Questões como o consumismo ou aspectos de cunho moral em relação ao corpo eram abordadas com frequência.

Na Figura 5, a representação de tipos femininos é associada pelos caricaturistas às questões da beleza e do consumo. Nas charges e cartuns é possível notar a associação das mulheres ao mundo relativo ao lar e ao universo do casamento tradicional - conforme pode ser observado no desenho situado no canto inferior esquerdo da Figura 5. Nesta charge, a mãe 


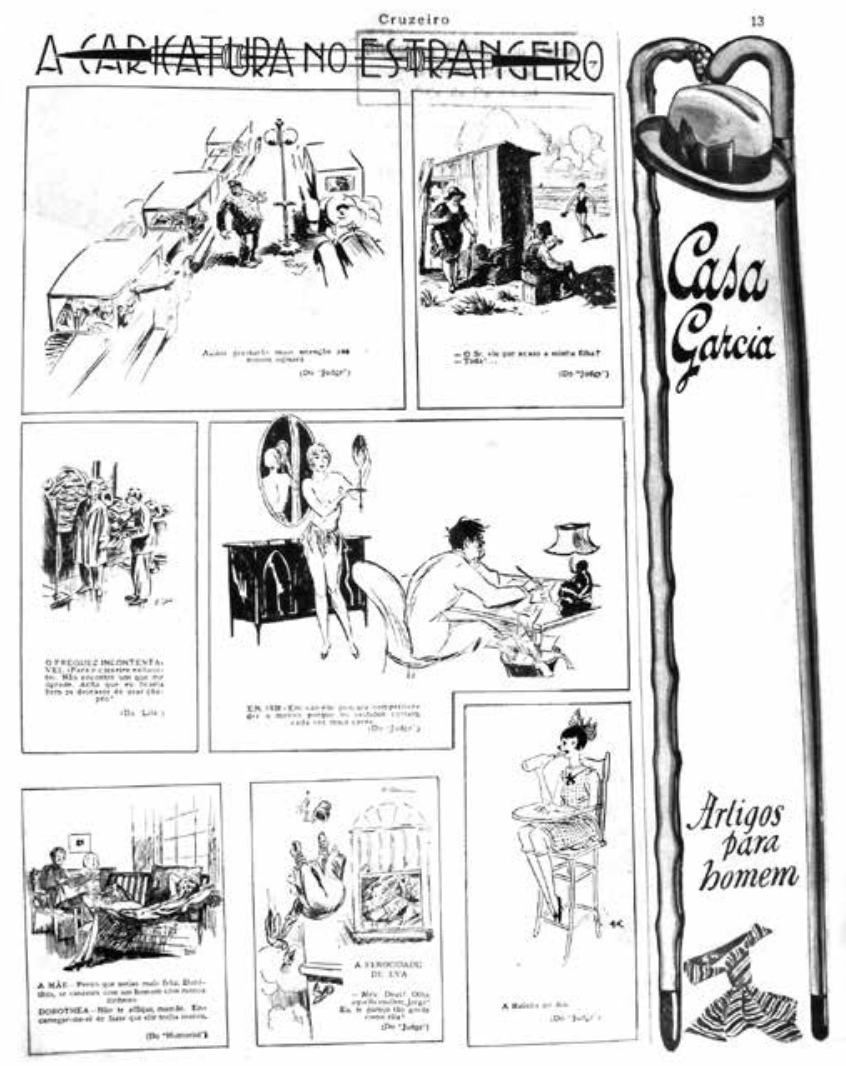

Figura 5

Coluna Caricatura no Estrangeiro. (O CRUZEIRO, 17 nov. 1928, p. 13)

diz à filha que ela seria mais feliz se escolhesse um homem menos rico para casar. A moça tranquiliza a mãe dizendo que não é preciso preocupação, pois ela mesma se encarregaria de deixar o futuro marido com menos dinheiro.

Durante os anos 20 e 30, assuntos ligados aos afazeres domésticos, à saúde, à estética e aos filhos, entre outros, eram tratados no sentido de instruir as mulheres, visando moldar o seu comportamento e seu caráter, conforme as charges à direita na Figura 5 que dão ênfase a questões estéticas. Neste sentido, um dos aspectos do "ser moderno", incluía nas suas entrelinhas um discurso em prol da conservação do matrimônio, que neste período ganha ênfase, uma vez que as inovações da "vida moderna" eram vistas por conservadores como ameaçadoras ao sistema familiar tradicional (MALUF; MOTT, 1998).

A sátira aos episódios cotidianos, incluindo nisso os próprios modelos de comportamento divulgados no periódico, era a proposta da seção PifPaf, que entra para o editorial do semanal 
em 1941. Escrita por Millôr Fernandes sob o pseudônimo de Vão Gogo e ilustrada por Péricles de Andrade Maranhão, a coluna abordava com bom humor os acontecimentos da semana com temáticas variadas (NETTO, 1998). Piadas, frases, notícias ironizadas e um "mini vocabulário" com palavras distorcidas visando zombar de algo ou de alguém eram os principais recursos utilizados. Esta seção, impressa a quatro cores, ocupava duas laudas, crescendo para meio caderno (8 páginas) em épocas festivas, como nas edições de Natal, em que eram feitas retrospectivas dos fatos marcantes que ocorreram no ano.

A Figura 6 mostra charges publicadas na coluna Pif-Paf, editada com o emprego de muita cor. Aqui o conteúdo textual é privilegiado, trazendo as charges como elementos complementares. Em contrapartida, a seção de cartuns Amigo da Onça traduz com poucas palavras e desenhos caricatos situações vividas por um homem "de ar ingênuo que causava as maiores confusões, muitas vezes tragédias, por causa de sua mania de dizer certas verdades em hora imprópria" (NETTO, 1998, p. 126). Esse personagem, também desenhado por Péricles de Andrade, tornou-se um dos maiores sucessos da revista $O$ Cruzeiro.

Figura 6 Coluna Pif-Paf (O CRUZEIRO, 17 ago. 1940)

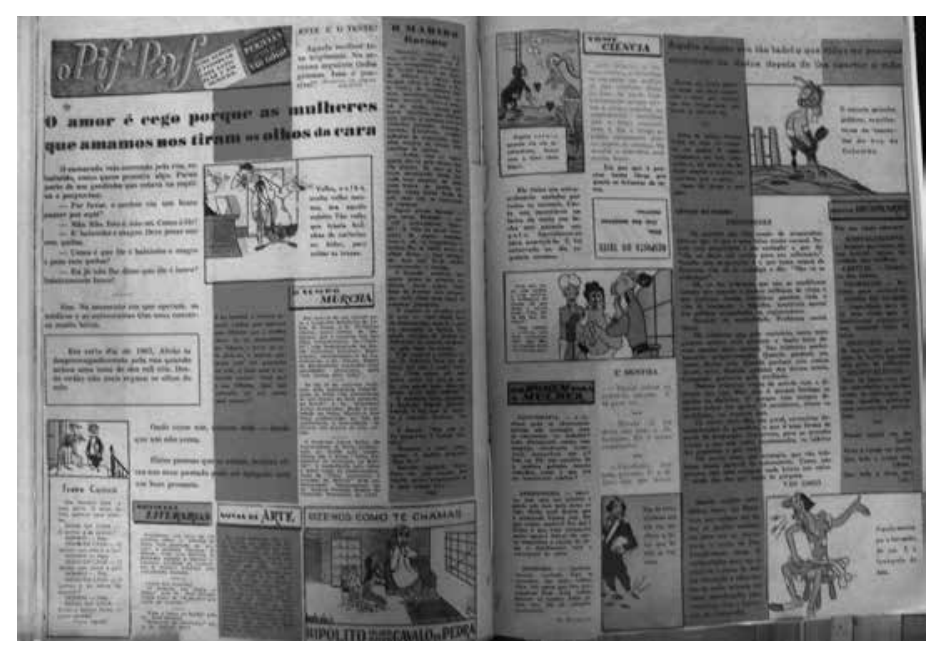

Nas ilustrações de humor, também destacam-se outros artistas, como Nássara, com suas caricaturas retratando indivíduos dos mais diversos segmentos, como músicos populares (O CRUZEIRO, 27 jan. 1945, p. 52-53) ou abordando casos históricos. Nas caricaturas de Nássara, o humor é vinculado a curiosidades educativas e informativas, fazendo uso de textos curtos ou médios e cores vibrantes. Vale ressaltar que as cores, 
por volta da década de 1940, passam a ser um elemento que agrega valores de modernidade ao semanal, em especial pelo maquinário renovado anos antes, abrindo caminho para novas possibilidades visuais.

Além das ilustrações, a fotografia também era explorada como recurso significativo na busca pela construção de significados resultantes da interação entre texto e imagem ${ }^{9}$. No exemplo da Figura 7, o espaço destinado ao texto apresenta-se reduzido a fim de valorizar as imagens. O tratamento conferido às fotografias localizadas no canto inferior esquerdo apresenta o uso de fios de contorno, demarcando os limites das imagens. A sobreposição é um recurso comum utilizado nas composições fotográficas no início da revista. Seguindo a tendência dos periódicos da época, tem-se na Figura 7 um exemplo com os tipos de sobreposições mais usuais. A interação entre imagens distintas também é vista na segunda lauda, em que o recorte da bandeira e do jogador sobreposto à foto subsequente favorece a sensação de diálogo entre elas, dispensando a necessidade de um conteúdo textual mais extenso e detalhado para a compreensão da notícia.

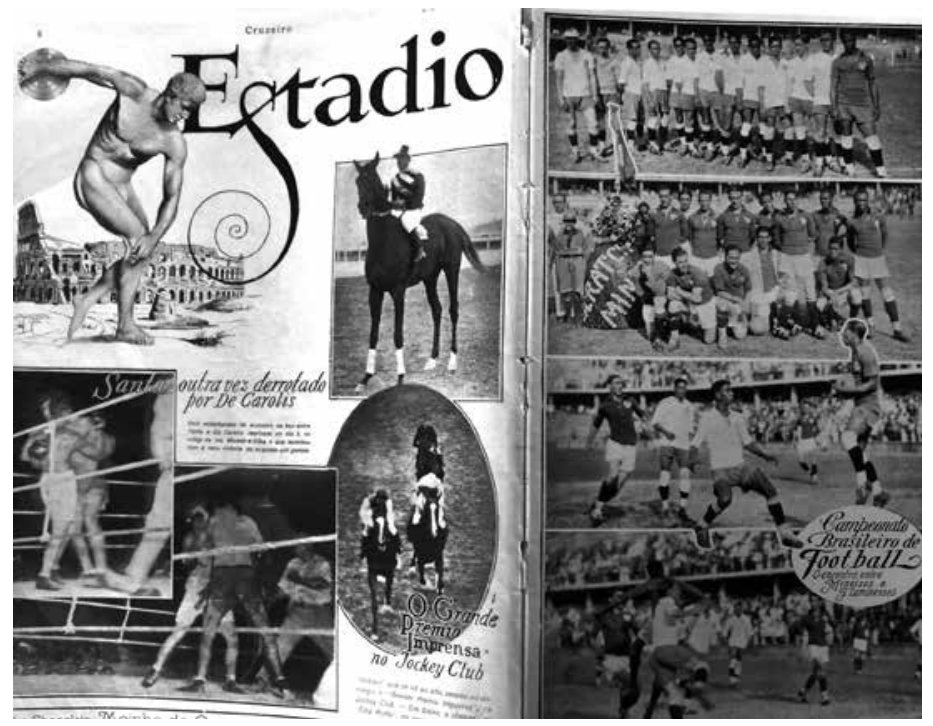

Enquanto a ilustração ganhava vida pelo maquinário de impressão em quatro cores, - mesmo que utilizado de forma limitada - a impressão de imagens fotográficas ainda encontrava-se no preto e branco. Entretanto, nota-se que antes da compra de maquinário novo para $O$ Cruzeiro, alternativas
Figura 7

Exemplo de tratamento fotográfico - Coluna Estádio. (O CRUZEIRO, 10 nov. 1928, p. 8-9). 
de tratamento na impressão de imagens fotográficas, como a coloração, foram utilizadas mediante a pintura de determinadas áreas da fotografia. Conforme pode ser visto nas imagens apresentadas na Figura 8 - que fazem parte de uma reportagem sobre o cotidiano de pessoas negras residentes em Pernambuco - a camisa do menino e os artefatos vendidos na feira de louça são realçados pelo emprego da cor vermelha. O recurso do recorte acompanhado da sobreposição também foi utilizado para interligar as imagens, conferindo riqueza na composição da página. É interessante observar a caracterização feita acerca das pessoas retratadas na reportagem. Na opinião da revista, elas estariam em uma condição "anterior à buzina do automóvel e aos arranha-céus", conservando suas tradições, em contraposição à "Recife que se moderniza a passos de gigante", que provavelmente seria representada por pessoas brancas (O CRUZEIRO, 8 dez. 1928, p. 43).

Retornando à questão da fotografia como uma profissão ainda não consolidada, havia uma demanda significativa por fotógrafos no O Cruzeiro. Em face da escassez de profissionais, a revista implementou em sua primeira edição concursos fotográficos mensais para suprir a demanda inicial por imagens que retratassem o cotidiano. Segundo o periódico, esses concursos possuíam o intuito de difundir e desenvolver a arte fotográfica "como meio documentário da vida e da natureza", valorizando e atribuindo ao fotógrafo os créditos pelos serviços prestados à revista (O CRUZEIRO, 10 nov. 1928, p. 44).

A fotografia jornalística em desenvolvimento também abordava temas como "a pobreza, a velhice, a doença, a diversidade cultural étnica e racial", assim como o trabalho feminino fora de casa (HIGONNET, 1991, p. 412). No que concerne à construção de valores associados às mulheres, estes temas coexistiram no período entreguerras com imagens que valorizavam a vida doméstica, a dedicação materna, o consumo e a individualidade, nas quais mulheres brancas das classes média e alta podem ser vistas, por vezes, em posição hierarquicamente superior às mulheres negras (HIGONNET, 1991). O periódico mostra tanto feminilidades relacionadas aos prazeres do lar e do consumo, quanto feminilidades associadas à realidade da necessidade de sustento familiar. Esta dualidade aparece com frequência no $O$ Cruzeiro durante as décadas focalizadas neste estudo.

Podemos ver um exemplo disso na Figura 8, que mostra a imagem de uma mulher que vende munguzá nas ruas de 


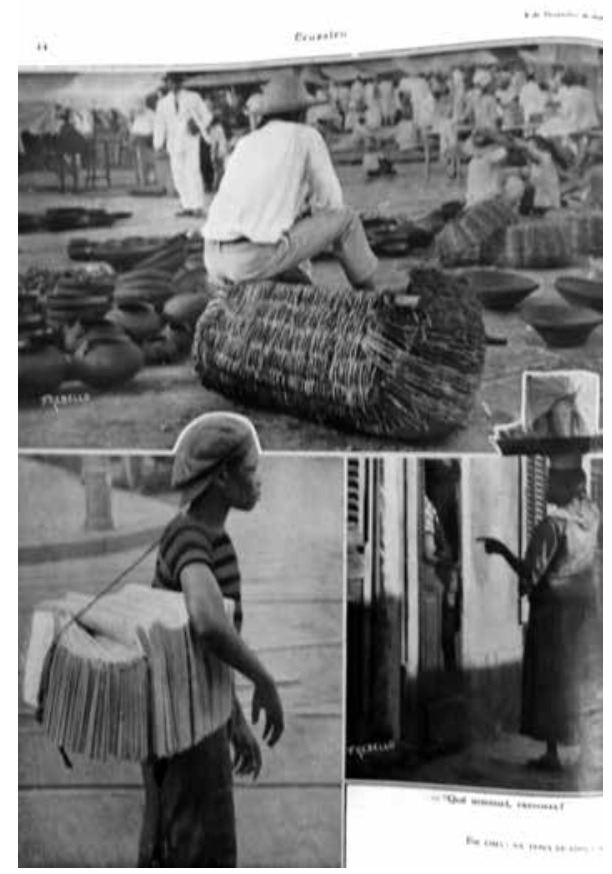

Recife. Na descrição da reportagem, ela e os demais indivíduos são vistos como figuras típicas, "das épocas passadas", "dos hábitos e costumes dos velhos tempos" (O CRUZEIRO, 8 dez. 1928, p. 43). Entretanto, ao trazer a imagem de uma a senhora exercendo atividades de comércio informal com fins de subsistência, o semanal põe em relevo as mulheres que encontravam-se fora dos moldes burgueses, estes últimos veiculados de forma privilegiada em O Cruzeiro, cuja existência, no entanto, apresentava-se como condição necessária para a manutenção das classes dominantes. A reportagem, também deixa transparecer certo tom de preconceito associado às mulheres das camadas baixas em comparação àquelas que não necessitavam trabalhar fora de casa, pois a incursão profissional na esfera pública suscitava questionamentos sobre aspectos relacionados à conduta moral e à honra das mulheres (SOIHET, 2006).

É possível ressaltar, através da comparação de duas imagens apresentadas anteriormente, como o conceito de modernidade atuou em conjunto com o desenvolvimento das técnicas de impressão. Enquanto na ilustração apresentada na Figura 2 tem-se o uso de impressoras mais desenvolvidas, demandando,
Figura 8

Alternativa de tratamento fotográfico utilizado no O Cruzeiro (O CRUZEIRO, 8 dez. 1928, p. 44) 


\section{W. PELAS CINCO PARTES Do MUNDOM!}

\section{NOVOS ASPIRANTES DA F. A. B.}

por conseguinte, menos recursos de pré-impressão, na fotografia da Figura 8 ocorre que, antes da impressão, houve um trabalho maior na preparação das matrizes, trazendo como resultado final recursos visuais bastante elaborados para a época.

Os usos da ilustração e da fotografia em O Cruzeiro exemplificam o resultado do desenvolvimento técnico na imprensa brasileira, que, acompanhando as mudanças tecnológicas e sociais, contribuíram para suprir a demanda por novas linguagens gráficas no período. Na tipografia, a resposta a essa demanda também se fez presente por meio do tratamento conferido aos tipos utilizados nas seções e matérias do semanal.

A Figura 9 apresenta alguns exemplos de títulos empregados nas principais seções do semanal. As imagens usadas para ilustrar os títulos podiam variar, e não obedeciam a um padrão definido, procedimento comum nas revistas ilustradas da primeira metade do século XX. Feitos manualmente, os tipos traziam características associadas ao conteúdo das seções. Nesses exemplos, a tipografia sem coloração, com serifas finas ou mesmo sem a presença delas, conferem seriedade e certa "universalidade" às matérias, tendo em vista que eram destinados ao público em geral.

Já as tipografias associadas às seções destinadas às temáticas entendidas como femininas, mostradas na Figura 10, ressaltam características como a delicadeza, a sensibilidade e o requinte, obtidas através do detalhamento dos tipos, do uso da cor e da distribuição do peso de cada letra. Em associação às imagens de mulheres, os tipos ganhavam maior clareza, no sentido de afirmar noções de gênero tradicionalmente reconhecidas como femininas.

A partir da década de 1940, os tipos passam a apresentar características que evocavam o dinamismo e a austeridade, de acordo com a natureza das reportagens. Alguns deles passam a ter mais peso, tramas e formas que variavam de uma edição para outra. Os relacionados aos interesses tidos como femininos traziam cores vibrantes, conforme os temas de cada seção.

Efeitos tipográficos são constantemente utilizados nas 

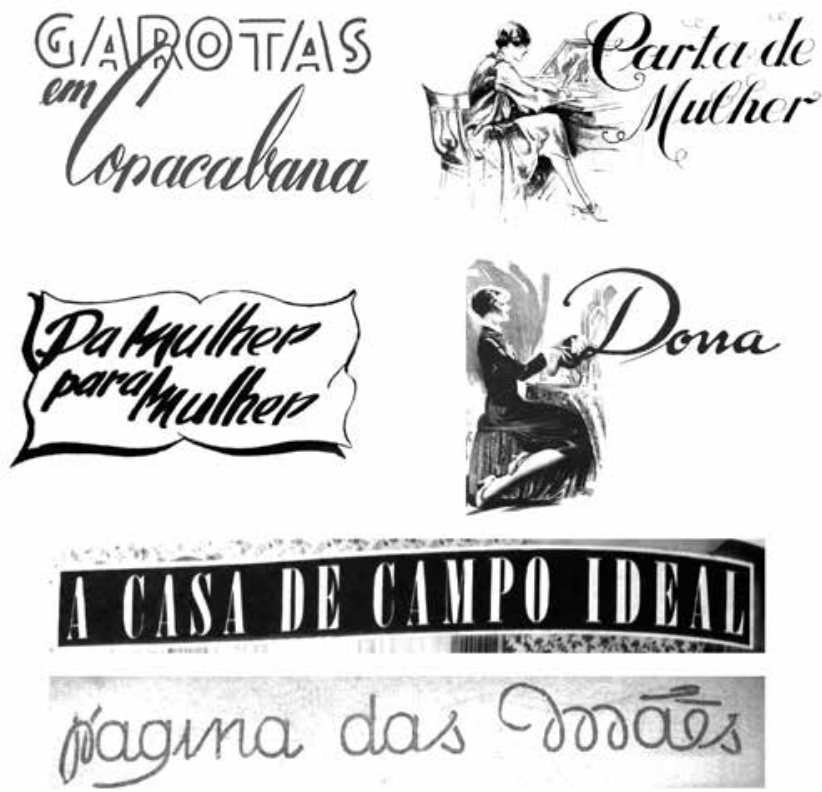

Figura 10

Exemplos de tipografias das colunas veiculadas na revista $O$ Cruzeiro entre 1928-1945. (Garotas em Copacabana. O CRUZEIRO, 1 jan. 1941); (Carta de Mulher. O CRUZEIRO, 17 nov. 1928);

(Da Mulher para Mulher. O CRUZEIRO, 1 set. 1945);

(Dona, O CRUZEIRO,

8 dez. 1928);

(A casa de campo ideal.

O CRUZEIRO, 11 ago. 1945);

(Páginas das mães.

O CRUZEIRO, 1 set. 1945)

reportagens no $O$ Cruzeiro. A relação de pioneirismo na concepção de títulos é vista principalmente nas primeiras edições, quando a revista buscava se fixar como a "mais moderna num país que cada dia se renova” (O CRUZEIRO, 28 nov. 1928, p. 2). O título da reportagem exibida na Figura 1 apresenta o emprego de um efeito que, mediante a integração das figuras com os caracteres do título, ratifica a proposta do semanal de suscitar visualmente a noção de modernidade.

$\mathrm{O}$ uso de fontes variava das clássicas serifadas, às mais modernas sem serifa, cujas formas mais puras e simplificadas remetem ao estilo Art Deco, com suas projeções futuristas, exaltando a técnica (SEVCENKO, 1998, p. 575). Passado e presente se encontram no semanário quando se trata de tipos, reflexo do período de transformações em que encontravam-se a imprensa e a indústria gráfica. Assim, a cultura visual desenvolve-se em conjunto com as tecnologias, as necessidades mercadológicas e em sintonia com a cultura de massas e do entretenimento em ascensão.

As capitulares também possuem diferenciações de acordo com o assunto da reportagem. A Figura 11 mostra dois exemplos. No artigo "Uma prodigiosa sorte de Cartas" a capitular letra "V" é ornamentada com naipes que remetem ao tema dos jogos de baralho. Na reportagem "O Rio Monumental e seus Arranha-Céos", a capitular "P", aparece sobre a imagem do "arranha-céu", 
Exemplo de capitular utilizada no semanal (O CRUZEIRO, 24 nov. 1928, p. 47)

buscando a associação com o conteúdo do texto, que se refere aos prédios construídos no Rio de Janeiro. A ornamentação das capitulares torna as reportagens mais atrativas do ponto de vista estético-visual e reforça mais uma vez a modernidade que a revista $O$ Cruzeiro propunha em seu editorial, sob o prisma das técnicas utilizadas. $\mathrm{O}$ uso de fontes variadas também pode ser percebido como um recurso que objetiva enfatizar a modernidade, mostrando ao público leitor as inúmeras possibilidades de rontextıalizarãก de 11 fato nor mein dos tinne

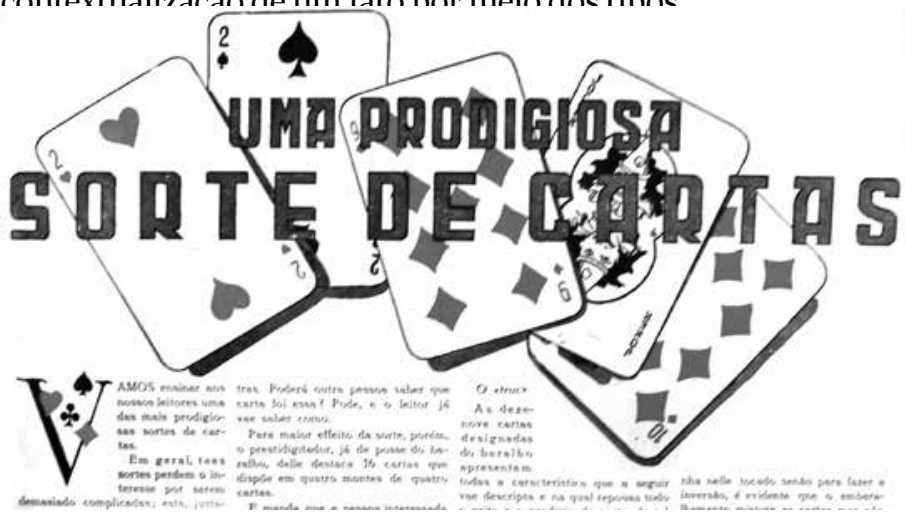

\section{Considerações finais}

No decorrer do texto foram ressaltados alguns dos aspectos gráficos que fizeram parte da construção de uma cultura visual moderna na revista $O$ Cruzeiro. Os exemplos apresentados são apenas uma amostra da variedade de recursos utilizados pelo semanal. Ao valorizar e investir no desenvolvimento de novas linguagens gráficas, o periódico objetivou atrair o público leitor por meio da identificação das experiências visuais proporcionadas pelo semanal com os ideais de modernidade que veiculava. Ao longo do espaço temporal estudado, o tema da modernidade se fez presente graficamente, mediante o suporte proporcionado, pelo uso de novas tecnologias, com destaque para a aquisição de máquinas impressoras de qualidade para a época.

Nesse sentido, ao pensar na modernidade como um processo que se inseriu de maneira desigual no país, o advento de novas linguagens gráficas tornou a informação mais acessível, principalmente através das revistas ilustradas. Com o uso massivo de fotografias e ilustrações, em conjunto com o aprimoramento gráfico, tais publicações contribuíram para a incorporação de novos hábitos de leitura ao cotidiano das pessoas. 
A originalidade e a sofisticação da visualidade desenvolvida revista $O$ Cruzeiro durante os seus primeiros 20 anos de circulação contribuiu para o reconhecimento do periódico como a mais influente publicação de circulação nacional no período.

\section{Referências}

CARDOSO, Rafael. Uma introdução à história do design. São Paulo: Edgard Blücher, 2000.

CARVALHO, Luiz Maklouf. Cobras criadas: David Nasser e O Cruzeiro. São Paulo: SENAC. São Paulo, 2001.

COSTA, Helouise. Surpresas da objetiva: novos modos de ver nas revistas ilustradas modernas. In: SAMAIN, Etienne (org.). Como pensam as imagens. Campinas: Editora da Unicamp, 2012, p. 153-173.

FIELL, Charlotte \& Peter. Design do Século XX. Lisboa: Taschen, 2000 .

FRANCISCHETT, Leandra. Submissão $\mathrm{x}$ independência: a ambivalência da imagem feminina nas fotorreportagens de O Cruzeiro. In: História, imagem e narrativas, n. 7, ano 3, UFF, Niterói, set./out. 2008. Disponível em: <http://www. historiaimagem.com.br/edicao7setembro20o8/submissao.pdf>. Acesso em: 16 ago. 2010.

HIGONNET, Anne. Mulheres, imagens e representações. In: DUBY, G.; PERROT, M. (Org.). História das mulheres no ocidente (séc. XIX), vol. 4. São Paulo: Ebradil, 1991, p. 402-427.

JÚNIOR, Gonçalo. A guerra dos gibis: a formação do mercado editorial brasileiro e a censura aos quadrinhos, 1933-64. São Paulo: Companhia das Letras, 2004, p. 91-94.

MALUF, Marina; MOTT, Maria Lúcia. Recônditos do Mundo Feminino. In: SEVCENKO, Nicolau. (Org.) História da Vida Privada no Brasil República, v. 3. São Paulo: Companhia das Letras, 1998, p. 367-421.

MORAIS, Fernando. Chatô: o rei do Brasil. São Paulo: Companhia das Letras, 1994.

NETTO, Accioly. O império de papel: os bastidores de O Cruzeiro. Porto Alegre: Sulina, 1998.

SEVCENKO, Nicolau. A capital irradiante: técnica, ritmos e ritos do Rio. In: SEVCENKO, Nicolau. (Org.) História da Vida Privada no Brasil República, v. 3. São Paulo: Companhia das Letras, 1998, p. 514-619.

SILVA, Geanne Paula de Oliveira. Revista no acervo: a coleção da Ilustração Brasileira (1935-1944). In: Cadernos de Pesquisa do CDHIS/UFU, ano 20, n. 36/37, UFU, Uberlândia, 2007, p. 
43-55. Disponível em: <http://www.seer.ufu.br/index.php/ cdhis/article/view/1179/116o >. Acesso em: 13 ago. 2010.

SOBRAL, Julieta. O desenhista invisível. Rio de Janeiro: Folha Seca, 2007.

SOIHET, Rachel. Mulheres pobres e violência no Brasil urbano. In: DEL PRIORE, Mary (Org.). História das mulheres no Brasil. 8. ed. São Paulo: Contexto, 2006, p. 362-40o.

VELLOSO, Monica Pimenta. Modernismo no Rio de Janeiro: turumas e quixotes. Rio de Janeiro: Editora Fundação Getúlio Vargas, 1996.

VELLOSO, Monica Pimenta. As distintas retóricas do moderno. In: OLIVEIRA, Cláudia de (Org.); VELLOSO, Monica Pimenta; LINS, Vera. O moderno em revistas: representações do Rio de Janeiro de 1890 a 1930. Rio de Janeiro: Garamond, 2010.

\section{NOTAS}

1. Os conceitos de modernidade e moderno para a linha editorial do $O$ Cruzeiro eram associados predominantemente ao progresso e ao desenvolvimento industrial. Entretanto, entende-se que tal visão possui caráter simplificador e generalizante por parte do periódico, não relativizando a complexidade do processo e a forma como estes termos se inseriram no cotidiano (VELLOSO, 1996).

2. Jean Manzon foi repórter fotográfico das revistas francesas Match, $V u$ e Paris Soir. Veio para o Brasil em 1940 e trabalhou para o DIP (Departamento de Imprensa e Propaganda) antes de integrar a equipe do O Cruzeiro. (MORAIS, 1994).

3. A ilustração citada possui características que lembram os cartazes do artista franco-ucreniano A. M. Cassandre, que atuava na Europa na mesma época do surgimento de $O$ Cruzeiro. Dentre estas características, destacamse os efeitos de dinamismo e a abstração geométrica (FIELL, 2000).

4. A filmagem citada foi resultado da permuta entre O Cruzeiro e a Metro Goldwyn Mayer, destacando a Multicolor como a mais moderna rotativa de que se tem notícia na época. Em troca, a revista $O$ Cruzeiro publicaria anúncios do estúdio de Hollywood (MORAIS, 1994).

5. Um caderno corresponde a 16 páginas impressas frente e verso.

6. Com veneno ou sem veneno. O Cruzeiro, 27 jan. 1945, p. 12-17.

7. Enfrentando os Xavantes. O Cruzeiro, 24 jun. 1944, s.n.

8. O Relógio do Morro. O Cruzeiro, 4 ago. 1945, p. 8-17.

9. Para uma abordagem mais aprofundada sobre o emprego da fotografia como recurso visual de vanguarda pelas revistas ilustradas durante a primeira metade do século XX, ver Helouise Costa (2012).

Recebido em: 01/10/13

Aceito em: 03/11/13 


\section{MARINÊS RIBEIRO DOS SANTOS \\ ribeiro@utfpr.edu.br}

Professora do Departamento Acadêmico de Desenho Industrial da Universidade Tecnológica Federal do Paraná desde 1995. Leciona nos cursos de Bacharelado em Design e Tecnologia em Design Gráfico e no Programa de Pós Graduação em Tecnologia. Fez Doutorado em Ciências Humanas na Universidade Federal de Santa Catarina, concluído em 2010. Seus interesses de pesquisa estão focados nos Estudos em Design, com ênfase nas relações entre cultura material e gênero.

\section{THAÍS MANNALA \\ thais.mannala@gmail.com}

Graduada em Tecnologia em Artes Gráficas pela Universidade Tecnológica Federal do Paraná (UTFPR) em 2011, com a monografia "Representações de feminilidades veiculadas no projeto gráfico da revista O Cruzeiro entre 1928-1945”. Atualmente é mestranda no Programa de Pós Graduação em Tecnologia (PPGTE-UTFPR), na Linha de Pesquisa Mediações e Culturas. 